controversial point is conclusively dealt with. The writer says :- "Again, though dimmed by heavy rain and thick fog, as it has been during the last few nights, the triple flash is always clear and unmistakable, and then produces, through the quasi-opaque atmosphere, and at a distance of thirty miles, the effect of the blurred disk of the moon on a small scale. This remarkable penetration power of the Tino light is conclusive proof, not only of how admirably it is designed and suited to its essential purpose as a guiding light under the peculiar atmospheric conditions of the Mediterranean, but also how hazardous it would be to dip-viz. to divert such a light, as has been suggested by some-from the horizon to the nearer sea in foggy weather, forsooth according to the bene placito of the man in charge, on the presumption that in such weather the luminous rays could not reach the horizon, and would therefore be wasted. This presumption is wholly fallacious in the Mediterranean, for in the Bay of Spezia, owing to its proximity to the Apennines, the rainfall is much greater than in other parts of the Tyrrhenean Sea, and banks of land fog can often be seen hanging over the bay and Tino, when the horizon as far as Leghorn, Gorgona, and even Corsica, is perfectly clear."

$$
\text { June I } 887 \text {. }
$$

J. KENWARD.

\section{REPORT OF THE BOARD OF TRADE ON WEIGHTS AND MEASURES.}

NE of the many official Reports which are laid annually before Parliament, but which unfortunately are not so carefully read by the general public as they might be, is a Report by the Board of Trade on their proceedings and business under the Weights and Measures Act of 1878. In Report No. 9, Sess. II., 1886, there is something of scientific interest to which we would invite the attention of our readers.

The only two units from which all Imperial measures and weights are derived are, as is well known, the yard and the pound, and material standards of these two units are deposited with the Board of Trade. The Act provides that an accurate copy of each of these standards is to be made, and an account of the verification of a new copy of the yard measure is given in the present Report. The results of the comparisons of the new yard, P.C. VI., with the Imperial standard yard No. I, show that it differs little from the original standard :-

$$
\text { P.C. VI. }=\text { No. } \mathrm{I}-0^{\circ} 0000034 \text { inch. } t=62^{\circ} \mathrm{F} \text {. }
$$

There are no two primary standards between which our present scientific methods cannot measure some difference, but the above two standards would appear to be as nearly alike as it is possible to make them.

In determining the rate of expansion by heat of the new standard yard (which is a bronze bar 36 inches long), it was found that with a rising temperature, the new bar expanded 0.000356 inch for $1^{\circ} \mathrm{F}$., but with a falling temperature it contracted at a lesser rate, $0^{\circ} 000343$ inch for $I^{\circ} F$. It is not stated whether this curious difference in the rate of expansion, as determined when the temperature is alternately rising and falling, is owing to the march of the mercurial thermometers or to other causes. Some doubt has arisen as to the rate of expansion of the metal (bronze) of which the Imperial standard was made. The thermometric expansions stated in the Report of the Astronomer-Royal on the construction of the Imperial standard (Phil. Trans. Roy. Soc., part iii., 1857, p. 6I) do not agree with those stated by Colonel Clarke and Sir Henry James in their Report on the comparisons of standards of length (1886). The actual rate of expansion of the Imperial yard was, in fact, not determined by the Standards Committee in 1857 , but was assumed to be the same as that of other similar bars of the same metal The more recent experience, however, is that no two bronze bars expand by heat at precisely the same rate, although they may be of the same dimensions, form, and material. The co-efficient of expansion of an alloy is slightly affected by differences in the age of the alloy, by its being subjected to extreme variations of heat and cold, and by peculiarities in molecular condition.

With reference to the metric system, we are glad to see that during 1886 standards of metric weight and measure were verified for certain authorities for use in scientific research or otherwise. It would, however, appear that in Japan, in the competition for commercial acceptance, the British system is at present outstripping the metric system.

The legal equivalent of the metre is 39.37079 inches, but, as some doubt has been expressed as to the scientific accuracy of this equivalent, Prof. W. A. Rogers, of Colby University, has undertaken to construct for the Standards Department a subdivided standard yard and metre, on which the precise length of the two standards shall be marked off, so that an exact inter-comparison of the two standards may, as far as practicable, hereafter be made at London and at the Bureau International des Poids et Mesures, at Paris.

In this Report we have for the first time complete and trustworthy information as to the standard weights and measures in use in China and Japan, Her Majesty's ministers at Pekin and Tokio having obtained the information from the native Governments and through the different local consuls.

During the year I 886 the Standards Department was specially engaged in the re-verification of the accuracy of its own standards, and in the issue to local authorities of some suggestions with reference to the duties of inspectors of weights and measures. Amongst the re-verifications particularly referred to we notice a memorandum on the re-verification of the gasmeasuring standards, a memorandum which shows the several conditions necessary for the accurate measurement of gas used for lighting purposes. The accuracy of the unit of volume, the cubic foot, is made to depend on the Imperial standard pound, and not on linear measurement. Experience has hitherto shown that the determination of the weight of a cubic foot of distilled water may best be made by means of a round vessel which holds a quantity of water equal to $62.32 \mathrm{I} \mathrm{lb}$. avoirdupois at $62^{\circ} \mathrm{F}$., rather than by a vessel of rectangular shape, which might be made to measure one foot in each of its dimensions. In this memorandum reference also is made to a slight difference in the methods of determining the zero, or freezing-points, of thermometers. It is, for instance, uncertain how long a thermometer should remain in melting ice or snow before its precise freezingpoint is noted. At the Bureau of Weights and Measures at Paris, for instance, the thermometer is only left in the pounded ice just long enough for it to reach the maximum of depression. With thermometers made of hard glass it is stated to be desirable not to hurry the observationsthe thermometers remaining long enough to allow the use of a micrometer, and several observations to be taken; but with other kinds of glass it is found to be desirable to be as quick as possible. This practice is also stated to be adopted at the Standards Offices at Berlin and Washington. On the other hand, at Kew the freezing-point of a thermometer is not observed until the instrument has been completely buried, both bulb and stem, up to $32^{\circ} \mathrm{F}$., or $0^{\circ} \mathrm{C}$., in well-pounded block ice for a period of not less than a quarter of an hour, care being always taken in cold weather to insure the whole of the ice being in a melting condition during the experiment by pouring a small quantity of tepid water over it from time to time.

Unlike the determinations of the rate of expansion of gas, there has not been made any determination of the rate of expansion of water which in exact experiments 
might be accepted as conclusive, and hence, in determining the weight of a volume of water at any given temperature, the Standards Department have been advised to adopt a mean result from several selected determinations, as those of Despretz, Kopp, and Pierre.

In many technical works, measurements of gas are erroneously referred to the temperature of $60^{\circ} \mathrm{F}$, and not to the legal temperature of $62^{\circ} \mathrm{F}$., at which temperature alone the standard foot contains 12 inches; the standard gallon ro lbs. weight of water; and the standard pound 7000 grains. It would appear that an error originally committed in certain hydrometer tables in taking $60^{\circ} \mathrm{F}$. instead of $62^{\circ} \mathrm{F}$, has been followed by many chemical authorities.

The weight of a cubic foot of ordinary air has been still taken by the Standards Department after the determinations of Regnault, as corrected by Moritz, Broch, and Agamemnone. The amount of carbonic acid present in ordinary air has been taken, after the inquiries of Parkes and Angus-Smith, at 6 volumes in every 10,000 volumes of air. If double the quantity, i 2 volumes, is present, as is sometimes the case in common rooms, it will make a difference of about 0.I 8 grain in the weight of the cubic foot of air. Ordinary air is still taken, after Regnault, as being two-thirds saturated with moisture.

In calculating the true weight of any given volume of air or of gas we may, of course, on very rare occasions have to allow for the accelerative effect of the force of gravity at the latitude of the place where the air or gas is weighed, as well as for the height of the place above sealevel. The normal latitude adopted in all such experiments is that of $45^{\circ}$ at sea-level.

For instance, the weight in grains of a cubic foot of ordinary air $\left(t=62^{\circ} \mathrm{F} ., \mathrm{B}=30\right.$ in.) at London (lat. $\left.=51^{\circ} 29^{\prime} 53^{\prime \prime}\right)$, at Edinburgh (lat. $\left.=55^{\circ} 57^{\prime} 20^{\prime \prime}\right)$, and at Dublin (lat. $=53^{\circ} 20^{\prime} 38^{\prime \prime}$ ), has been taken as follows :-

\begin{tabular}{|c|c|c|c|}
\hline & Dry air. & $\begin{array}{l}\text { Air two-thirds } \\
\text { saturated. }\end{array}$ & $\begin{array}{c}\text { Moist air } \\
\text { saturation = I }\end{array}$ \\
\hline & $\begin{array}{r}G \\
534\end{array}$ & $\begin{array}{c}G r . \\
531^{\circ} 92\end{array}$ & \\
\hline$\ldots$ & $534 \cdot 30$ & $53 \mathrm{I} \cdot 8 \mathrm{I}$ & \\
\hline n $\quad \ldots . \ldots \ldots \ldots$ & $534 \cdot 21$ & $531 \cdot 72$ & $530 \cdot 48$ \\
\hline
\end{tabular}

From time to time, on the application of local authorities, suggestions are issued by the Board of Trade as to the best modes of testing the weights, measures, and measuring instruments used for commercial purposes. In this country the local inspectors are not bound to follow official instructions as they are in other countries, but are free to carry out their technical work in such a way as the Justices and Town Councils may approve. It is therefore only by the issue of such official suggestions that uniformity of local practice can be at all reached, and some amount of co-ordination and local effectiveness thereby secured. It is perhaps to be regretted that there is in this country no central authority like the Normal Aichungs Kommission of Germany or Austria to give force and life to the whole local system; not that we would have the local officers in this country drilled to the dull sameness of official uniformity in the way they are drilled by some Continental Governments, but the absence of a proper scientific training by our local inspectors often leads to complaints from traders and manufacturers. By these official suggestions the Board of Trade endeavour, therefore, to educate local officers in their technical work and to keep them so far in touch with modern progress.

The present Report contains a paper on the testing of weighing-machines, which should be of really practical use to the local officers, for it is the first time that any instructions have been published as to the mode of testing such machines.

Amongst other appendixes to this Report we find papers relating to the well-known model apparatus, designed by Sir F. Abel, for testing the flashing-point of petroleum; abstracts of returns from local officers; notes on the sale of coal by weight and the sale of intoxicants by measure-with reference to which it would appear that there is more petty fraud than ever amongst traders; and a note on the average current weight of the sovereign. In the latter note reference is made to a number of weighings of gold coin, which have been recently made at the leading Banks in London. The results of these weighings show that most of the gold coinage in circulation has really ceased to be legal tender as to weight. Nearly all the coins which were weighed were found to be slightly below the least current weight allowed by the Coinage Act. If the present law, which requires receivers of light gold coins to cut or deface them, were really obeyed, then it would appear from this note that six sovereigns out of every seven ought strictly to be cut or defaced. This seems to be a worse state of things than when Prof. Jevons made his well-known report on the metallic currency of the United Kingdom in 1868 .

\section{THE GERMAN METEOROLOGICAL OFFICE.}

A HISTORY of the Royal Prussian Meteorological A Institute from the time of its establishment in 1847 until its re-organisation in 1885 , by Dr. G. Hellmann, has just been published in the year-book of the Institution, "Ergebnisse der Meteorologischen Beobachtungen im Jahre 1885 " (Berlin, 1887,246 pages, large 4to, with plates). Dr. Hellmann is well-known to students of meteorology by many very valuable articles, and especially by his laborious compilation of a "Repertorium der Deutschen Meteorologie," containing a list of the articles, inventions, and observations in the domain of Meteorology and Terrestrial Magnetism in Germany from the earliest times down to the year I88 I (Leipzig, 1883, 995 pages, large 8vo). The kingdom of Prussia was relatively late in organising a regular system of observations, Baden and Bavaria in Southern Germany having established well-appointed services before the end of the last century; and Würtemberg followed with its system in $I_{\delta 2} \mathrm{I}-2$. The want of trustworthy data for Northern Germany was much felt by Baron A. von Humboldt at the time of the construction of his first isothermal charts in 1817 , and the establishment of the service in Prussia was due to the urgent representations which he made to the present Emperor. In I 847 a system of 25-30 stations was established under Dr. Mahlmann, and observations were taken at the hours of 6,2 , and ro; these hours have been generally adhered to both in Germany and Austria down to the present time. Before commencing operations, all the stations were duly inspected, and suitable observers selected, mostly from teachers in the upper schools. While neither instruments nor remuneration are provided for such observers in this country, in the Prussian system an annual allowance, varying from about $£ 7$ Ios. upwards, according to circumstances, is made to many of the observers, together with an outfit of instruments. The result of these arrangements has been that probably in no other system upon the globe have so many useful works been published by the various observers, upon whom generally devolved the task of working up their own observations. Dr. Mahlmann having died suddenly on one of his tours of inspection, his work was taken up in April 1849 by the late eminent Prof. $\mathrm{H}$. W. Dove, of the University of Berlin, and his first care was to revise the observations hitherto taken and to publish them in a first Report of the Observations taken in 1848-9. The publication of this Report induced several other states to join the Prussian system, many of the observers now taking up the work without remuneration, and this active cooperation enabled Dove to publish for 1855, and for subsequent years, a summary of observations for each month of the year for Northern Germany, and in 1858 a first sketch of the climatological conditions based upon ten years' observations. Prior to this publication these 